Discussion Paper No. 05-62

\title{
Alternative Approaches to Discrete Working Time Choice in an AGE Framework
}

Melanie Arntz, Stefan Boeters and Nicole Gürtzgen

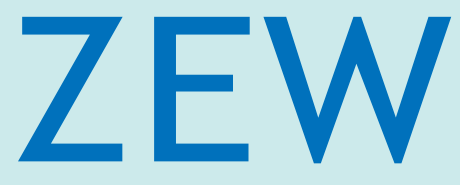

Zentrum für Europäische Wirtschaftsforschung $\mathrm{GmbH}$

Centre for European

Economic Research 
Discussion Paper No. 05-62

\section{Alternative Approaches to Discrete Working Time Choice in an AGE Framework}

Melanie Arntz, Stefan Boeters and Nicole Gürtzgen

Download this ZEW Discussion Paper from our ftp server:

ftp://ftp.zew.de/pub/zew-docs/dp/dp0562.pdf

Die Discussion Papers dienen einer möglichst schnellen Verbreitung von neueren Forschungsarbeiten des ZEW. Die Beiträge liegen in alleiniger Verantwortung der Autoren und stellen nicht notwendigerweise die Meinung des ZEW dar.

Discussion Papers are intended to make results of ZEW research promptly available to other economists in order to encourage discussion and suggestions for revisions. The authors are solely responsible for the contents which do not necessarily represent the opinion of the ZEW. 


\section{Non-technical summary}

We present a model that integrates the discrete working time choice of heterogenous households into a general equilibrium setting where wages are determined by sectoral bargaining between firms and trade unions. The model integrates microeconometric work based on microsimulation models and macroeconomic experiences with representative agent models. Basically, it is an applied general equilibrium (AGE) model with 26 different household types. Each of them represents a different socioeconomic group. Each person chooses from a small number of working time options, among them non-participation. The net income associated with each working time option is endogenously determined and depends on flexible producer wages as well as taxes and transfers.

In the practical application of this model the exact formulation of the discrete working time choice turned out to be a crucial aspect for the model outcomes. There are two principal alternatives: (1) in the Dutch MIMIC model (Graafland et al., 2001) household heterogeneity (within household types) results from an autonomous working time preference parameter, and (2) a conventional logit setup includes a stochastic idiosyncratic term in the formulation of household preferences for the individual working time options (van Soest 1995). In this paper we perform a detailed comparison and assessment of these two different approaches. We use both variants to analyse stylised policy reforms that are designed to stimulate labour supply by a cut in the basic social assistance rate and lower transfer withdrawal rates We report macroeconomic changes as well as effects on the participation rate, average working hours and labour supply for different subsets of households.

Against the background of a number of difficulties with the approach that uses an autonomous working time preference parameter, the logit alternative is preferable. The main advantage results from its direct compatibility with the underlying estimation and simulation of labour supply reactions in a standard microsimulation model. The problems of the logit setup - mainly the IIA implication - is less severe and can be approached using established econometric techniques. All in all, we see the logit approach as the more promising option in a general equilibrium framework combining comprehensiveness, detail and consistency in applied research. 


\title{
Alternative Approaches to Discrete Working Time Choice in an AGE Framework
}

\author{
Melanie Arntz, Stefan Boeters*, Nicole Gürtzgen \\ Centre for European Economic Research, Mannheim
}

July 2005

\begin{abstract}
We compare two options of integrating discrete working time choice of heterogenous households into a general equilibrium model. The first, known from the literature, produces household heterogeneity through a working time preference parameter. We contrast this with a model that directly incorporates a logit discrete-choice approach into a AGE framework. On the grounds of both calibration consistency and adequate accomodation of within-household interaction, we argue that the logit approach is preferable.
\end{abstract}

Keywords: applied general equilibrium, discrete working time choice, labour market, wage bargaining, labour market reform, logit model

JEL Code: D58, J22, J51

*Corresponding author: Stefan Boeters, Centre for European Economic Research, PO Box 103443, D-68034 Mannheim, e-mail: s.boeters@cpb.nl. We benefitted from comments by Michael Feil and Egbert Jongen on an earlier draft of this paper. 


\section{Introduction}

Persistent unemployment at high levels remains at the top of the political agenda in many European countries. While experience during the last decade has not been so uniform that it would be justified to speak of the European unemployment problem (Nickell and van Ours, 2000), unemployment rates are still significantly higher than the OECD average (OECD 2004). The problems are particularly concentrated at the lower end of the skill distribution where negative demand effects from skill-biased technological change and shifting world trade patterns adversely interact with disincentives resulting from the tax and transfer schemes. As demand conditions can only - if at all - be influenced indirectly, policy reform proposals tend to focus on altering the negative incentives resulting from the se-called "poverty trap", i.e. the combination of a (too) small difference between the welfare benefits when non-employed and net earnings at low wage levels, and a (too) high transfer withdrawal rate. Economic commentators agree that reforms are necessary here, but concrete policy proposals face two main difficulties. A reduction in the transfer level would mean a lump-sum income loss for those who are actually not able to work. This runs counter to the general redistributive goals of the tax and transfer schemes that are characteristic of the "European system". In addition, lower transfer withdrawal rates usually lead to windfall profits for those workers who are in the respective income bracket and do work already. These windfall profits and the ensuing tax revenue losses can be so large that reforms of that sort are judged not to be financially feasible.

Therefore, any labour market reform that aims at increasing work incentives at the lower end of the skill distribution needs to be carefully tailored both with respect to the target groups to which it applies and the exact values of the tax and transfer rates. This means that such reforms affect individuals on the labour market in different ways and to a different extent. If we want to assess such reforms ex ante, we need economic models that are capable of capturing the heterogeneous conditions on the labour market and the specific behaviour of different worker groups. Microsimulation methods are normally considered the adequate choice for such kind of analysis (Gupta and Kapur, 2000). However, if specifically tailored labour market reforms are actually successful in stimulating the labour market, they have potentially large macroeconomic repercussions through the adjustment of wages and the need to balance the public budget. The adequate instrument for such economy wide interactions is applied general equilibrium (AGE) analysis (Shoven 
and Whalley, 1984).

We therefore advocate a model that integrates the general equilibrium approach and microsimulation features like heterogeneous households and discrete labour supply options (Boeters, Gürtzgen and Schnabel, 2003, Boeters, Feil and Gürtzgen, 2004). In our model, which is based on the AGE model PACE-L (Böhringer, Boeters, and Feil, 2005), we have 26 different households representing different socioeconomic groups. The households choose from a small number of working time options, among them non-participation. For each of these options the net income is endogenously determined and depends on flexible producer wages as well as taxes and transfers.

In the practical application of this model the exact formulation of the discrete working time choice turned out to be a crucial aspect for the model outcomes. There are two principal alternatives: (1) in the Dutch MIMIC model (Graafland et al., 2001) household heterogeneity (within household types) results from an autonomous working time preference parameter, and (2) a conventional logit setup includes a stochastic idiosyncratic term in the formulation of household preferences for the individual working time options (van Soest 1995). In this paper we perform a detailed comparison and assessment of these two different approaches.

The focus of our comparison might seem relatively narrow if the model is seen from a greater distance, but we think that it is justified given certain deficiencies of alternative modelling strands. Therefore we here briefly put the model in the broader context of the literature that is directed at a model-based assessment of tax and transfer reforms on the labour market.

One type of models used in that context are AGE models with a single representative household. Hutton and Ruocco (1999) is an important example for this approach. It is possible to reach a considerable degree of heterogeneity in such a model (male vs. female labour supply, part-time vs. full-time jobs, different skill categories), but there remains a principal problem. The extensive and the intensive margin of labour supply cannot properly be distinguished. There remains an ambiguity between a labour supply increase that is due to higher working hours and one that is due to higher participation. This proves detrimental to the clearness of the analysis both when it comes to the calculation of actual transfer payments and when the model is to be calibrated with empirical labour supply elasticities. (The same problems are encountered in Böhringer et al., 2005.) 
The distinction between the intensive and the extensive margin of labour supply is explicitly accounted for in a family of models in which households are heterogeneous with respect to the fixed costs of labour market participation and choose from a continuous set of working time options (e.g. Saez 2002, Kleven and Kreiner 2003, Immervoll et al., 2004). Such models are mainly used for the discussion of the marginal cost of public founds and for the design of optimal redistribution systems. However, they generate results in which the participation rate is flexible, but all active households (of a specific type) choose the same working time. This makes it difficult to mimic the heterogeneity of actual hours-ofwork patterns except for a very deep disaggregation of households. In addition, the use of these models causes problems if the hours-of-work options that are made more attactive through a policy reform do not coincide with the average working time - as it is the case with reforms encouraging part time work.

The remainder of the paper is organised as follows. In Sections 2 and 3, we describe in detail the two alternative core labour supply modules of our model and their calibration to the output of a microsimulation model. Section 4 then gives a brief overview of the general equilibrium frame in which the labour supply modules are embedded. Section 5 reports the results of the comparative scenario analysis. We simulate cuts in the social assistance level and changes in the transfer withdrawal rate and describe to what extent the results are sensitive to the assumptions about labour supply. In Section 6, we summarise and draw conclusions. An appendix provides additional information about the aggregation structure of the model and the German tax and transfer system.

\section{Two approaches to discrete working time choice}

At the core of our comparative study is the discrete-choice (DC) labour supply of heterogeneous households. In this section, we describe two alternative ways of modelling labour supply, which both have a considerable amount of intuitive appeal and have been used in applied economic work. However, as we later show in our simulations, they can lead to considerably diverging results. The first variant described (Section 2.1) refers to the to-date exclusive AGE model application of DC labour supply. This is an idea from the Dutch MIMIC model (Graafland et al., 2001), in which household heterogeneity (within household types) results from an autonomous working time preference parameter. The 
second variant (Section 2.2) is the logit setup, in which household preferences for the individual working time options include a stochastic idiosyncratic term. This is the standard approach for the econometric analysis of discrete labour supply choice (van Soest 1995), though until now it has not been combined with an AGE framework.

\subsection{The autonomous working time preference approach}

The Dutch MIMIC model (Graafland and de Mooij, 1999, Bovenberg et al, 2000, Graafland et al., 2001) was the first AGE model that included a discrete-choice labour supply module. The central idea of the MIMIC modelling approach to discrete labour supply is that a conventional CES utility function (with consumption and leisure as arguments) is complemented by an additive part which captures heterogeneity in working hours preferences and varies over households (even within one household type). The complete MIMIC model contains a number of further details (disaggregation of leisure, black work, household production) that make it difficult to highlight its distinctive features in labour supply modelling and raise a number of additional calibration problems. Therefore in this paper we draw on a modified version of the MIMIC labour supply module, which was used for policy analysis in Boeters, Gürtzgen and Schnabel (2003) and Boeters, Feil and Gürtzgen (2004). We refer to this approach as "AWTP" (for "Autonomous Working Time Preference").

The representative household of a basic AGE model is first broken down into a number of household types, $j$, characterised by sociodemographic variables. Within each type, households are heterogeneous with respect to the preference for working hours. We first show the algebraic formulation of the heterogeneity-generating mechanism for the simpler case of a single (as compared to couple) household. The utility function of a household of type $j$ and working-time preferences $i$ is given in eq. (1).

$$
U_{i, j}\left(h_{j, k}\right)=\left[\alpha_{j}^{L}\left(T-h_{j, k}\right)^{\frac{\sigma_{j}-1}{\sigma_{j}}}+\left(1-\alpha_{j}^{L}\right) C_{j}\left(h_{j, k}\right)^{\frac{\sigma_{j}-1}{\sigma_{j}}}\right]^{\frac{\sigma_{j}}{\sigma_{j}-1}}-\beta_{j}\left(\left|h_{j, k}-\bar{h}_{j, i}\right|\right),
$$

Utility is defined over a discrete set of working time options $h$, indexed by $k$ and varying over household types. Working time enters utility in three ways: In the first part of the utility function it reduces leisure (the difference to total time endowment, $T$ ) and is connected to consumption ${ }^{1}, C$, through the wage level and the rules of the tax and transfer

\footnotetext{
${ }^{1}$ We use a static approach and assume that consumption equals income.
} 
system. In the second part of the utility function it produces a difference to autonomously desired working time, which linearly reduces utility. Heterogeneity within a household type is generated through the parameter of desired working time, $\bar{h}_{j, i}$. Heterogeneity between household types is captured in the parameters $\alpha_{j}^{L}$ (share parameter of leisure), $\sigma_{j}$ (elasticity of substitution within the CES part) and $\beta_{j}$ (weighting parameter for the working-hours difference).

The approach for couples is analogous, but two-dimensional. The joint utility function of couples depends on the hours combinations $\left(h_{j, k}^{f}, h_{j, l}^{m}\right)$, where the individual spouses are indexed by $i$ and $g$ and the superscripts $f$ and $m$ refer to women and men, respectively:

$$
\begin{array}{r}
U_{g, i, j}\left(h_{j, k}^{f}, h_{j, l}^{m}\right)=\left[\alpha_{j}^{L}\left(L_{j}\left(h_{j, k}^{f}, h_{j, l}^{m}\right)\right)^{\frac{\sigma_{j}-1}{\sigma_{j}}}+\left(1-\alpha_{j}^{L}\right)\left(C_{j}\left(h_{j, k}^{f}, h_{j, l}^{m}\right)\right)^{\frac{\sigma_{j}-1}{\sigma_{j}}}\right]^{\frac{\sigma_{j}}{\sigma_{j-1}}} \\
-\beta_{j}^{f}\left(\left|h_{j, k}^{f}-\bar{h}_{j, i}^{f}\right|\right)-\beta_{j}^{m}\left(\left|h_{j, l}^{m}-\bar{h}_{j, g}^{m}\right|\right) .
\end{array}
$$

$L_{j}\left(h_{j, k}^{f}, h_{j, l}^{m}\right)$ denotes joint leisure of the couple and is defined as

$$
L_{j}\left(h_{j, k}^{f}, h_{j, l}^{m}\right)=\left(\alpha_{j}^{f}\left(T-h_{j, k}^{f}\right)+\left(1-\alpha_{j}^{f}\right)\left(T-h_{j, l}^{m}\right)\right),
$$

with $\alpha_{j}^{f}$ representing a weighting parameter for female leisure and $C_{j}\left(h_{j, k}^{f}, h_{j, l}^{m}\right)$ denoting average joint consumption. In the following, we explain the basic steps of the determination of the labour supply choice by the simpler case of singles according to (1).

For each individual there are several distinct labour market states, which result from three dichotomies: (1) Each individual can be either voluntarily unemployed (supplying zero hours of work) or participate in the labour market. This is part of the discrete labour supply choice. (2) If the individuals supply positive hours of work, they are either employed or involuntarily unemployed. The probability of unemployment is endogenously determined in general equilibrium. (3) In the event of involuntary unemployment, the individuals are either eligible for unemployment benefits or not. The probability of benefit eligibility is derived from the benchmark data set and held fixed.

We calculate the expected value of consumption $C_{j}\left(h_{j, k}\right)$ as a weighted average over the three labour market states (employed, unemployed with or without unemployment benefit entitlement) with the respective probabilites. More detail concerning the calculation of 
the disposable income is provided in Appendix A.6. For given parameters of the utility function (still to be calibrated, see Section 3), we can calculate the CES part of the utility function for each hours of work option, $U_{i, j}^{C E S}\left(h_{j, k}\right)$, which is independent of the idiosyncratic parameter $\bar{h}_{i, j}$. The values of $U_{i, j}^{C E S}\left(h_{j, k}\right)$ for two adjacent working time options determine the critical values of $\bar{h}_{j, i}$ that delimit the individuals who prefer the lower hours-of-work option from those who prefer the upper. We denote the critical value of $\bar{h}_{j, i}$ for household type $j$ between hours of work category $k$ and $k+1$ with $\bar{h}_{j, k, k+1}$ and calculate it as

$$
\bar{h}_{j, k, k+1}=\frac{h_{j, k}+h_{j, k+1}}{2}+\frac{U_{i, j}^{C E S}\left(h_{j, k}\right)-U_{i, j}^{C E S}\left(h_{j, k+1}\right)}{2 \beta_{j}} .
$$

If the CES utility for both hours-of-work options is the same, the critical value of $\bar{h}$ lies exactly half way between both. If one CES utility is higher than the other, the critical value of $\bar{h}_{j}$ is asymmetrical, and the extent of the asymmetry is determined by the value of $\beta_{j}$. The critical values of $\bar{h}_{j}$ are crucial both for the calibration of the model (see Section 3) and the policy simulations. A change in the tax and transfer system affects the disposable income of the households. This bears on the CES utilities and thus the relative attractiveness of the different working time options. The critical values of $\bar{h}_{j}$ adjust, which, depending on the distribution of the $\bar{h}_{j, i}$ within the household types, finally determines the frequencies of the different working time categories.

For couple households, working time is determined in an analogous manner. Each couple household chooses from a two-dimensional set of working-time options. We disassemble the simultaneous maximisation problem of the household into two independent working time choices of the partners by assuming that when one partner chooses their optimal working time, they take the other partner's income and leisure to be constant at their conditional expected values given the benchmark probabilities. ${ }^{2}$ In this way, we obtain independent critical values of $\bar{h}$ for both partners.

The most important feature of the AWTP setup for the simulation outcomes is that the critical values of $\bar{h}$ only depend on the characteristics of the adjacent working-time

\footnotetext{
${ }^{2}$ The simultaneous maximisation of female and male working hours would encounter difficulties because multiple local maxima are possible. (Given that the woman works longer, it is optimal for the man to work less, and vice versa.) This would require an explicit comparison of absolute utility values, which doesn't match well with the overall mixed-complementarity set-up of the numerical model. Furthermore, it is likely to result in discontinuous reactions of the households, when they switch from one local equilibrium to another.
} 
options. If we make one working-time option more attractive through a modification of the tax and transfer system, this will increase its "basin of attraction" (those values of $\bar{h}$ that lead to the choice of this very option) at the cost of the options directly below and above. Other options are not affected. Specifically, in the case of an isolated loss of income for non-participation, individuals will only move into the lowest working-time option. The consequences of this model setup in concrete scenarios will be highlighted in Section 5 .

\subsection{The logit approach}

If one approaches the discrete choice of working time from an econometric angle, the multinomial logit setup is the natural starting point. Among the econometric tools for analysing discrete choice it is the simplest one and often used as a benchmark for more advanced models (for an overview see Train, 2003). Adoptions of the logit model to an AGE setting are rare, however. Among the few exceptions are the TREMOVE model (De Ceuster et al, 2004), in which the logit approach is used for modelling the demand for different car types, and WorldScan (Lejour et al., 1999), where it is used for modelling international capital mobility. We know of no examples of a combination of logit discrete choice and AGE modelling in a labour market context.

The simplest discrete choice setup is when the utility of each option is a combination of a deterministic part, $\bar{U}$, that depends on a vector of the characteristics of the options, $x_{k}$, and an additive stochastic term. For household type $j$ we then have

$$
U_{j}\left(x_{k}\right)=\bar{U}_{j}\left(x_{j, k}\right)+\varepsilon_{j, k}
$$

The distinctive feature of the logit approach is that the error term, $\varepsilon_{k}$, is assumed to be independently standard extreme-value distributed. Under this assumption there is an explicit formula for the probability of preferring option $k$ over all other options $l$ from a set $m$ (McFadden, 1974):

$$
P\left(U_{j, k}>U_{j, l}\right)=\frac{\exp \left(\bar{U}_{j}\left(x_{j, k}\right)\right)}{\sum_{m} \exp \left(\bar{U}_{j}\left(x_{j, m}\right)\right)}, \quad \forall l \neq k
$$

In a general equilibrium framework, where a large number of equations must be solved simultaneously, such an explicit expression for the choice probabilities is of great advantage. In other discrete choice approaches (probit or mixed logit) the choice probabilities 
can only be calculated by numerical integral evaluation. In principle it would be possible to combine this with general equilibrium equations, but in models that are highly disaggregated this would go beyond what is computationally feasible.

In our case, $x_{j, k}$ is a vector of characteristics the hours-of-work options that includes disposable income and weekly hours of leisure time for men and women,

$$
x_{j, k}=\left(\log \left(C_{j}\left(h_{j, k}^{f}, h_{j, l}^{m}\right)\right), \log \left(T-h_{j, k}^{f}\right), \log \left(T-h_{j, l}^{m}\right)\right),
$$

where the individual components are calculated in the same way as in the AWTP approach. We follow van Soest (1995) in assuming a quadratic utility function with $A$ and $\beta$ as parameters that capture the quadratic and linear terms, respectively.

$$
\bar{U}_{j}\left(x_{j, k}\right)=x_{j, k}^{\prime} A_{j} x_{j, k}+\beta_{j}^{\prime} x_{j, k}
$$

The parameters $A$ and $\beta$ are estimated using the microsimulation model described in the next section.

In contrast to the AWTP model, under the logit approach shifting is possible between all working-time options. If we increase the attractiveness of one option in isolation, all other options will be chosen less frequently, not only the adjacent ones. More specifically, a characteristic feature of the basic logit approach is the independence of irrelevant alternatives (IIA), which means that each of the other options loses probability exactly in proportion to the benchmark frequencies. (This property is relaxed in approaches like probit, mixed or nested logit.) In the simulations in Section 5, we will demonstrate the consequences of this feature in practical policy analysis.

\section{Calibration of the labour supply module}

The point of departure for the calibration of both model variants presented in Section 2 is a labour supply estimation based on the ZEW microsimulation model (Buslei and Steiner, 1999, Steiner and Jacobebbinghaus, 2003). We describe the estimation procedure briefly in Section 3.1 and explain in Section 3.2 how we use it to generate the model parameters. 


\subsection{Underlying econometric estimation of labour supply reac- tions}

The ZEW microsimulation model combines a calculator for the household income under the current German tax and transfer system with a discrete choice labour supply estimation that follows van Soest (1995). The coefficients of the utility function (3) are estimated based on the 1999 wave of the German Socio-Economic Panel (GSOEP), using the maximum likelihood criterion. We estimate the coefficients separately for couples, female singles and male singles. In each of these three estimations, it is assumed that both linear and quadratic coefficients differ between individuals, i.e. all coefficients are broken down into a constant as well as terms that interact with a number of individual and household-related characteristics (age, dummy for citizenship, East Germany, handicaps and children in certain age brackets). These interactions account for differences in the preferences of households and individuals for certain hours-of-work options. Additional constant terms capture fixed costs of working. For singles we include a constant for all positive hours categories; for couples, there are two constants, one for positive working hours of the woman, the other for both spouses working. Appendix A.3 reports details of the estimation.

\subsection{Generation of calibrated model parameters}

While the labour supply estimation works at the level of individual households, both labour supply modules of the AGE model use 26 aggregated representative household types. These households differ by household composition and skill of the members, 10 of which are single households and 16 couple households. More detail of the disaggregation is provided in Table 7 in the appendix. Each individual (single or spouse) can choose from a fixed number of discrete labour supply options. For married males, there are three labour supply options. For all other individuals (married women, single females and males) there are five options. The discrete options have been chosen so that they correspond to the empirical distribution of labour supply behaviour of the different types of individuals (Buslei and Steiner, 1999). For all individuals the first option is non-participation (zero hours of work). The options are summarized in table 8 in the appendix.

Some of the parameters needed for the calibration of the AGE model can be taken 
directly from the GSOEP data set. These are: (1) the shares of the 26 household types in the total population, (2) the distribution of household labour supply within each household type, and (3) the probabilities of receiving either unemployment benefits or social assistance payments if unemployed.

For calibrating the labour supply responses in the AWTP version of the labour supply module, we use partial ${ }^{3}$ own-price elasticities of labour supply. These partial elasticities have been simulated for each household type with the parameters resulting from the estimation at the individual data level (see Table 11 in the appendix).

The calibration procedure is set up to determine simultaneously two sets of parameters: the parameters of the CES part of the utility function $\left(\alpha_{j}^{L}, \sigma_{j}\right.$ and $\beta_{j}$ for singles, $\alpha_{j}^{L}, \alpha_{j}^{f}, \sigma_{j}$, $\beta_{j}^{f}$ and $\beta_{j}^{m}$ for couples) and the parameters of the distribution of the autonomous working time preference parameter, $\bar{h}$, across individuals. We assume $\bar{h}$ to be distributed over the interval $[0,70]$ in a stepwise uniform distribution. The steps of this distribution coincide with the critical values of $\bar{h}$, which delimit households that fall into different workinghours categories. This means that all individuals working $h_{k}$ hours in the benchmark situation are uniformly distributed between $\bar{h}_{k-1, k}$ and $\bar{h}_{k, k+1}$. These steps in the density distribution are then held fixed in the subsequent counterfactual analysis. The stepwise uniform distribution is flexible enough to exactly reproduce the empirical working-hours distribution in the model. In the case of couple households, the density distribution to be adjusted is two-dimensional. It is composed of 15 cells, each with a uniform probability density.

We calibrate the parameters of the CES utility part so as to optimally reproduce the elasticities simulated with the microsimulation model. For given parameter values, we determine analytically the elasticities that result in the model by calculating how a rise in the wage in one working-time category affects the disposable household income of households that supply labour in this category. Through the CES part of the utility function, the change in consumption leads to an adjustment of the critical values of $\bar{h}$. Some households characterised by values of $\bar{h}$ that are close to the critical values in the benchmark will change labour supply categories. However, as the density of the distribution of the $\bar{h}$ is discontinuous at the critical value, the elasticity of the model will be different whether we increase or lower the wage. We take the average of these two

\footnotetext{
${ }^{3}$ Percentage point changes of the probabilities in relation to per cent changes in the wage.
} 
reactions to match the empirical elasticities,

$$
\eta_{j, k}=w_{k} \frac{d C}{d w_{k}}\left(1-\alpha_{j}^{L}\right)\left(\frac{U_{j, h_{k}}^{C E S}}{C_{j, h_{k}}}\right)^{\frac{1}{\sigma_{l}}} \frac{f_{j, k-1}+2 f_{j, k}+f_{j, k+1}}{2 \beta_{j}},
$$

where $f_{j, k}$ is the density of $\bar{h}_{j}$ between $\bar{h}_{j, k-1, k}$ and $\bar{h}_{j, k, k+1}$, and $\eta_{j, k}$ is the corresponding empirical elasticity.

In equation (4) we have three free parameters for each single household $\left(\alpha_{j}^{L}, \sigma_{j}\right.$ and $\left.\beta_{j}\right)$ and five for couple households $\left(\alpha_{j}^{L}, \alpha_{j}^{f}, \sigma_{j}, \beta_{j}^{f}\right.$ and $\left.\beta_{j}^{m}\right)$. However, the effect of variations in these parameters on the elasticities is very similar and nearly linear in the relevant range. This means individual parameter values are not well identified when we solve the numerical problem of optimally adjusting to the empirical elasticities. Therefore, we arbitrarily fix the value of $\sigma_{j}$ for all households at 2 , which stabilises the determination of the other parameter values. The values of the calibrated elasticities are only slightly affected by this procedure. Table 11 in the appendix compares the elasticities that result from our calibration procedure with the simulated elasticities from the microsimulation model. The table makes clear that our model is fairly good in approximating the overall level of labour supply reactions. However, with respect to the ranking of the elasticities across the different working time categories, it is rather inflexible.

The calibration of the logit labour supply module is considerably more straightforward, because its basic structure is the same as in the estimation of the labour supply parameters. The only difference is that we now work at the level of the 26 representative household types instead of the individual level. For generating the parameter values of the household types, we compute unweighted arithmetic means of all individual parameters falling into the respective type. The resulting aggregated parameters can be found in Table 12 in the appendix.

\section{An AGE framework with decentralised wage bar- gaining}

The labour supply module is embedded into a computable general equilibrium model of Germany ("PACE-L"). In this section, we only sketch the other parts of the model. Most 
focus is on the wage determination module of PACE-L, which, through the wage bargaining mechanism, directly interacts with the labour supply decision of the households. An extensive, algebraic model description and a summary of the data sources used for calibration can be found in Böhringer et al (2005).

\section{Labour Market}

Wages are determined by sector-specific bargaining between an employers' association and a trade union. The bargaining outcome is represented as the maximisation of a Nash function, which includes the objective functions of both parties and their respective fallback options. We adopt the "right to manage" approach: Parties bargain over wages, and firms determine labour demand on the basis of the bargained wage. The union represents two types of workers, high skilled and low skilled. For each skill type, the union's objective function is calculated as employment times the value of a job minus the value of unemployment. The values of the labour market states are recursively determined as weighted averages of the incomes in the case of employment and unemployment, where the weights are computed from the transition probabilities between the labour market states (see Pissarides, 1990, for an overview of the search-and-matching approach).

We assume that the trade union is utilitarian with respect to the different household types. The marginal tax rates and the values of the states of employment and unemployment are therefore calculated as weighted averages over all households and working-time categories. In turn, the wage that results from bargaining in general equilibrium is used to derive the income positions of all households in all possible labour market states. In order to preserve continuity of the model, this dependence is linearly approximated. We calculate an average and a marginal rate of the total tax and transfer effects for each household and labour market state in the benchmark. These are treated as parameters in the counterfactual policy simulations.

The two labour markets for low and high skilled labour are balanced by aggregating on the demand side over sectors and on the supply side over household types. We assume that with respect to household types the structure of labour demand is uniform across sectors. The households captured by the microsimulation model include all households with flexible time allocation and observable hours of work, which is about $60 \%$ of total labour supply. Pensioners, students, women on maternity leave, civil servants and the self-employed are excluded in the microsimulation model. In the general equilibrium model, they are 
represented by an additional aggregate household with fixed labour supply. Householdspecific unemployment rates are aggregated into economy-wide unemployment per skill group. Changes in aggregate unemployment are distributed among household types in proportion to their benchmark unemployment.

In a wage-bargaining setting, the wages respond to reforms in the tax and transfer system through two different channels. First, the reforms change the marginal burden of the total tax and transfer system (either through an explicit change of tax rates or through lower transfer withdrawal rates). This bears on the bargaining outcome through the average skill-specific effective marginal tax rates. However, the effect of a specific reform on the average marginal tax rate is normally not clear a priori, because in most cases the marginal burden increases for some individuals while it decreases for others. With a constant average tax rate, an increase in the effective marginal tax rate raises the degree of tax progression, which leads to wage moderation on the part of the unions (Koskela and Vilmunen 1996). Second, reforms of the transfer system reduce expected income when being unemployed (and thus the fall-back position of unions) in two ways: directly through lower transfer payments and - if they succeed in stimulating labour supply - indirectly through a higher probability of unemployment (at given labour demand).

\section{Firms}

In each production sector, a representative firm produces a homogenous output. The production function is of the nested constant-elasticity-of-substitution (CES) type, combining intermediate inputs, capital and labour of the two skill types. Each individual firm is assumed to be small in relation to its respective sector. All firms in one sector interact through monopolistic competition. This means that firms can exploit market power in their respective market segment. Cost minimisation yields demand functions for the primary factors at the sectoral level and corresponding uncompensated (own and cross) price elasticities for labour that are used in the Nash bargaining FOCs. Capital is mobile across sectors, and the market for capital is perfectly competitive. In the simulations in Section 5 we additionally assume that capital is internationally immobile, which reflects a short- to medium-run model horizon.

\section{Private households}

We distinguish the 26 representative worker households, one dummy household with fixed labour supply, and a capitalist household. The capitalist household receives all capital 
and profit income. Capitalists decide over consumption and investment according to the approach of Ballard et al. (1985). Their utility function is calibrated to empirical saving elasticities. Worker households, by contrast, do not save. The structure of consumption is assumed to be identical across all households. Aggregate consumption is distributed among the different consumption goods according to a CES function.

\section{Government}

The main focus in the model of this paper is on the complex tax and transfer system for private households, which are calculated in a special programme module (see Appendix A.6) and then linearly approximated through two sets of parameters: an average and a marginal tax and transfer rate for each household type in each labour supply category and each labour market state. Apart from the taxes and transfers for the private households, the government collects the following taxes: a uniform capital input tax, a profit tax, an output tax in production, and a differentiated consumption tax on all consumption commodities. The government budget contains the revenue from all these taxes, the public purchases of goods, and the balance of payments surplus or deficit.

\section{Foreign Trade}

Domestically produced goods are converted through a constant-elasticity-of-transformation function into specific goods destined for the domestic market and the export market, respectively. By the small-open-economy assumption, export and import prices in foreign currency are not affected by the behaviour of the domestic economy. Analogously to the export side, we adopt the Armington assumption of product heterogeneity for the import side. A CES function characterises the choice between imported and domestically produced varieties of the same good. The Armington good enters intermediate and final demand. Foreign closure of the model is warranted through the balance-of-payments constraint.

\section{Policy Simulations: Does the approach to discrete choice matter?}

In this section, we apply the model to simulate social welfare reforms that are designed to stimulate labour market participation of low-income workers. Germany's social assistance 
system in its present state is particularly suited for our demonstration purposes since it produces strong labour market disincentives as discussed above. The benefit level is widely considered too generous from an incentive point of view, and transfer withdrawal results in effective marginal tax rates that are close to 100 percent at the bottom of the income distribution. Figure 1 illustrates the relationship between gross and net monthly labour earnings as well as disposable income for a single person without children. The grey line depicts net earnings, whereas the black line (labelled 'status quo') represents disposable income in the benchmark. Disposable income starts at $600 €$, which is the social assistance level for this household type. Benefits are phased out at a rate of approximately 80 per cent up to the break even income, where eligibility ends. ${ }^{4}$

Figure 1: Income function of a single without children

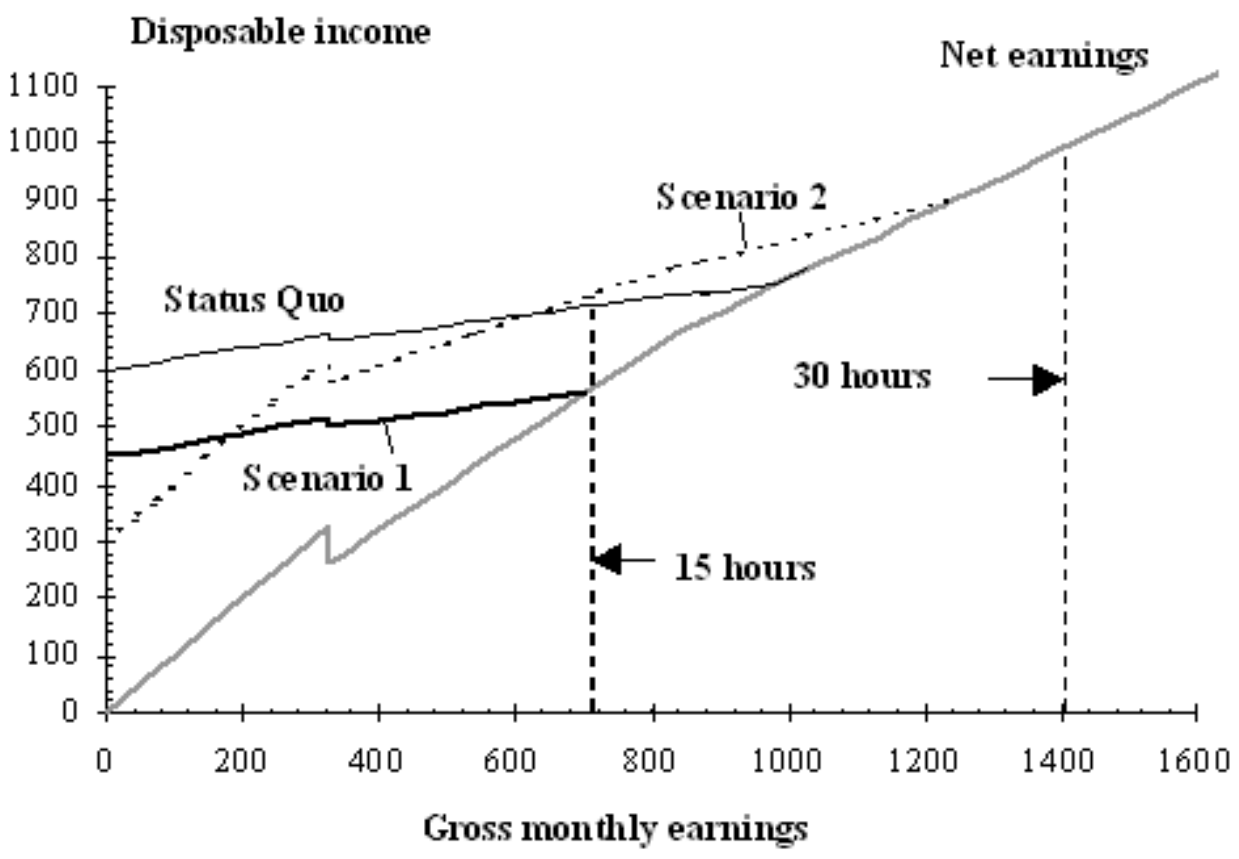

The two policy scenarios explored in our analysis are chosen in order to illuminate the similarities and differences in the two modelling approaches. It is not our primary aim to compare the labour market effects in the two scenarios per se. A study directed at the

$4 " 15 "$ and "30 hours" in Figure 1 refer to a weekly labour supply of a worker with a gross hourly wage of $10.8 €$. 
comparison of different policy reform proposals is Boeters, Gürtzgen and Schnabel (2003). The following section describes the scenarios in more detail. The simulation outcomes are then presented in two stages: first, partial equilibrium results to highlight the different working mechanisms of the two labour supply modules, and second, general equilibrium results that include the interaction with the wage bargaining institutions.

\subsection{Reform Scenarios}

\section{Scenario 1}

In the first scenario, we reduce the basic social assistance rate by 50 per cent for those welfare recipients who are able to work. For a single person without children, for example, this means a 25 per cent cut in the benefit level (from roughly $600 €$ to $450 €$ ). From Figure 1 , where the new budget constraint is represented by the bold black line, it can be seen that this scenario leaves the difference in disposable incomes between non-participation and the first working time category (15 hours) virtually unchanged. This means that incentives to take up a part-time job do not increase, whereas higher working time categories become considerably more attractive relative to non-participation. In such a setting, the logit approach may be expected to produce substantially larger participation effects than the AWTP approach since it allows individuals to switch from non-participation to all possible working-time options. In the AWTP approach, in contrast, individuals are restricted to switch to adjacent working-time categories.

\section{Scenario 2}

In the second scenario, the cut in social assistance payments is more radical, but combined with a reduction in the transfer withdrawal rate. We fully abolish the basic social assistance rate, which means a 50 per cent lower benefit level (300 €) for a single person without children. This is combined with cutting the transfer withdrawal rate to zero up to the net earnings level that is necessary to reach status-quo social assistance. ${ }^{5}$ E.g., a single person without children may now earn $300 €$ net labour income that is not withdrawn. Net earnings in excess of this amount are subject to a transfer withdrawal rate

\footnotetext{
${ }^{5}$ The transfer withdrawal rate for non-employable single individuals remains the same as in the statusquo system, whereas employable partners of non-employable persons in couple households face a lower transfer withdrawal rate.
} 
of 50 per cent up to the break even income where net income corresponds exactly to disposable income. For a single person without children, eligibility for social assistance therefore extends up to net earnings of $900 €$ (see the dashed line in Figure 1). In contrast to Scenario 1, Scenario 2 substantially widens the gap in disposable income between nonparticipation and the first working time category. Hence, taking up a part-time job now becomes considerably more attractive. This change in incentives is captured in both modelling approaches (AWTP and logit), so that we can expect the differences in simulated changes in the participation rates to be smaller in Scenario 2 than in Scenario 1.

\subsection{Partial equilibrium results}

We first present partial equilibrium results, where gross wages are held fixed and the public budget is not balanced through adjustment of some tax. These results allow us to focus on the changes in the relative attractiveness of the labour supply options that solely result from the policy measures. The comparison of the alternative labour supply modules is thus simplified.

\section{Scenario 1}

In Table 1, we exemplify the labour supply responses in Scenario 1 for one particular household type (low-skilled female singles without children) under the two different sets of model assumptions (AWTP and logit).

\begin{tabular}{cccc}
\hline \hline Hours category & $\begin{array}{c}\text { Benchmark } \\
\text { share (per cent) }\end{array}$ & $\begin{array}{c}\text { Scenario 1 } \\
\text { AWTP }\end{array}$ & $\begin{array}{c}\text { Scenario 1 } \\
\text { Logit }\end{array}$ \\
\hline 0 & 24.6 & 24.0 & 20.7 \\
15 & 22.7 & 20.5 & 16.9 \\
30 & 5.9 & 8.7 & 11.8 \\
38 & 29.9 & 29.9 & 33.3 \\
47 & 16.9 & 16.9 & 17.3 \\
\hline \hline
\end{tabular}

Table 1: Hours distribution (single women without children)

Scenario 1 lowers the disposable incomes for hours categories ' 0 ' and '15', but leaves the difference between them nearly unchanged. 30 (and more) hours, however, become 
relatively more attractive (see Figure 1). For the 'AWTP reactions' only changes in the relative attractiveness of adjacent working time categories are relevant. As a consequence, the main result here is a shift from 15 hours of labour supply to 30 hours. Because the relative attractiveness of full-time jobs compared to 30 hours is left unchanged, full-time and overtime work are completely unaffected. Virtually the same is the case for the participation rate, which goes up only slightly by 0.6 percentage points. By contrast, the equilibrium distribution produced by the logit approach (last column of Table 1) diverges considerably more from the benchmark distribution. Particularly the participation reaction (3.9 percentage points) is stronger than under the AWTP assumptions. The reason is that individuals now may change to all hours categories that become more attractive relative to non-participation, not only the adjacent ones. As a result, the logit simulations produce an increase in the frequencies of all categories over 15 hours, while non-participation and 15 hours work is reduced.

\begin{tabular}{lcccccc}
\hline \hline $\begin{array}{l}\text { Individual } \\
\text { group }\end{array}$ & PR & AWT & TLS & PR & AWT & TLS \\
\hline Married men & 0.73 & -0.07 & 0.71 & 2.44 & -0.37 & 2.23 \\
Married women & 0.42 & -0.34 & 0.22 & 1.47 & -1.14 & 0.80 \\
Singles & 0.60 & -0.23 & 0.44 & 1.02 & 0.59 & 1.65 \\
Low-skilled & 0.59 & -0.01 & 0.71 & 1.90 & -0.42 & 2.40 \\
High-skilled & 0.58 & -0.08 & 0.48 & 1.66 & -0.36 & 1.60 \\
All & 0.58 & -0.19 & 0.51 & 1.69 & -0.30 & 1.70 \\
\hline \hline PR: participation rate (change in percentage points), AWT: average \\
working time (change in per cent), TLS: total labour supply in hours \\
(change in per cent)
\end{tabular}

Table 2: Partial labour supply effects Scenario 1)

While Table 1 was confined to one particular household type, Table 2 presents the effects on participation rates, average working time and supplied hours of work for different sub-groups of individuals. The effects for these sub-groups depend on the magnitude of the household-specific labour supply elasticities and the overall distribution of household types. The aggregate participation reactions under both approaches show a similar pattern to that in Table 1. For all subaggregates, increases in participation rates are less 
pronounced under the AWTP approach; logit produces effects that are almost three times as large. A further notable difference is in the average working time effects of those individuals supplying positive hours of work (AWT). Under the AWTP approach, an increase in the participation rate comes along with a reduction in average working time because switches are only into the lowest working time category. Under the logit approach, this is not necessarily the case since individuals may switch to all possible working hours categories. The average working time of singles, for example, increases by 0.59 per cent. Under both approaches, the effect on total labour supply (TLS) is positive because the decrease in working time is dominated by the increase in participation rates.

\section{Scenario 2}

Table 3 reports the partial equilibrium labour supply responses for Scenario 2, again for low-skilled female singles without children. From Figure 1 it can be seen that in this scenario taking up a part-time job in the lowest hours category becomes considerably more attractive since the income gap between non-participation and a 15-hours job is substantially enlarged.

\begin{tabular}{cccc}
\hline \hline Hours category & $\begin{array}{c}\text { Benchmark } \\
\text { share (per cent) }\end{array}$ & $\begin{array}{c}\text { Scenario 2 } \\
\text { AWTP }\end{array}$ & $\begin{array}{c}\text { Scenario 2 } \\
\text { Logit }\end{array}$ \\
\hline 0 & 24.6 & 17.1 & 15.4 \\
15 & 22.7 & 29.6 & 23.8 \\
30 & 5.9 & 6.6 & 10.8 \\
38 & 29.9 & 29.9 & 32.8 \\
47 & 16.9 & 16.9 & 17.2 \\
\hline \hline
\end{tabular}

Table 3: Hours distribution single women without children)

The incentive to switch from non-participation to a 15-hours job is similarly well captured by both approaches, AWTP and logit. As a result, the simulated participation responses are now considerably closer together than in Scenario 1 (logit: + 9.2 \%-p., AWTP: + $7.5 \%$-p.). But again, while in the AWTP case additional participation is concentrated on the 15-hours category, the logit simulations produce an increase in the frequencies of all positive hours-of-work categories. 


\begin{tabular}{lcccccc}
\hline \hline Individual & \multicolumn{3}{c}{ AWTP } & \multicolumn{3}{c}{ Logit } \\
group & PR & AWT & TLS & PR & AWT & TLS \\
\hline Married men & 1.19 & -0.17 & 1.10 & 1.42 & -0.38 & 1.13 \\
Married women & 0.92 & -0.92 & 0.39 & 1.55 & -1.35 & 0.85 \\
Singles & 2.36 & -1.62 & 0.97 & 2.03 & -0.64 & 1.47 \\
Low-skilled & 2.02 & -0.24 & 1.35 & 2.85 & -0.58 & 2.37 \\
High-skilled & 1.32 & -0.16 & 0.82 & 1.43 & -0.34 & 0.99 \\
All & 1.42 & -0.81 & 0.88 & 1.64 & -0.73 & 1.16 \\
\hline \hline
\end{tabular}

PR: participation rate (change in percentage points), AWT: average working time (change in per cent), TLS: total labour supply in hours (change in per cent)

Table 4: Partial labour supply effects (Scenario 2)

Table 4 reports participation, working time and labour supply effects for different subaggregates. The results of Table 3 can be generalised: For most groups, participation effects are lower under the AWTP assumptions, but the difference between the two labour supply modules is considerably smaller than in Scenario 1. The aggregate increase in participation in the logit case exceeds the response under AWTP by only 15 per cent (+ $1.64 \%$-p. as compared to $+1.42 \%$-p.).

The participation responses in couple households deserve a closer look. Under the AWTP assumptions, participation reactions of married men are more pronounced than those of married women. This is counterintuitive since couple women generally have larger labour supply elasticities and exhibit considerably higher non-participation rates. The fact that married men nevertheless react stronger when using the AWTP approach results from the difference in working time categories open to men and women in connection with the AWTP-specific patterns of switches between options. For men in couples, entering the labour force always takes the form of moving into a full-time job. Married women, in contrast, are restricted to switch to 9.5 hours of work. For men, the participation decision is thus connected to a larger income difference, and this leads to the more pronounced participation effect in the AWTP module. The restrictions imposed by different working hour categories for married men and women are also present in the logit approach, but there they do not matter that much. Here, married women are found to react stronger than their male counterparts, as one would expect, since all positive hours-of-work categories 
are available to them ${ }^{6}$.

The difference between the approaches in the change of total labour supply is larger than the difference in participation responses. This is because the logit simulations produce a smaller decrease in average working time than the AWTP approach, where average working time decreases for all subgroups of individuals.

\subsection{General equilibrium results}

We now turn to the general equilibrium effects which take into account the equilibrium wage responses, the labour demand reactions and the adjustment in the marginal income tax chosen to warrant revenue neutrality of the reforms.

\section{Scenario 1}

Table 5 reports the general equilibrium effects on participation rates and total labour supply as well as changes in equilibrium wages, unemployment rates and effective marginal tax rates for Scenario 1.

\begin{tabular}{lcccccccccc}
\hline \hline Individual & \multicolumn{4}{c}{ AWTP } & \multicolumn{1}{c}{ Logit } \\
group & PR & TLS & W & UR & TM & PR & TLS & W & UR & TM \\
\hline Married men & 0.71 & 0.70 & & & & 1.73 & 1.50 & & & \\
Married women & 0.40 & 0.21 & & & & 1.19 & 0.56 & & & \\
Singles & 0.59 & 0.44 & & & & 0.90 & 1.38 & & & \\
Low-skilled & 0.57 & 0.70 & -0.52 & 0.09 & -2.40 & 1.63 & 2.13 & -0.93 & 1.58 & -2.27 \\
High-skilled & 0.57 & 0.47 & -0.72 & 0.03 & -0.46 & 1.24 & 1.10 & -2.13 & 0.66 & -0.40 \\
All & 0.57 & 0.50 & & & & 1.30 & 1.23 & & & \\
\hline \hline
\end{tabular}

PR: participation rate (change in percentage points), TLS: total labour supply in hours (change in per cent), W: gross wage (change in per cent), UR: unemployment rate (change in percentage points), TM: marginal tax rate (change in percentage points)

Table 5: General equilibrium effects (Scenario 1)

\footnotetext{
${ }^{6}$ Note that this is not the case in Scenario 1. Even though the gap between male and female participation responses is narrowed under the Logit approach, men still react more pronounced (see Table 2). The reason is that for couple men all available working time categories become more attractive relative to non-participation, whereas for women the relative attractiveness of the lowest category (9.5 hours) is left unchanged.
} 
Compared to the partial equilibrium effects (Table 2), general equilibrium labour supply responses are mitigated due to the negative impact the reform has on wages. Under both approaches, the reform leads to a stronger downward pressure on high-skilled as compared to low-skilled wages. This can be traced back to differences in the change in the effective marginal tax rates, which - by the tax progression argument (Koskela and Vilmunen, 1996) - bears on the bargaining behaviour of the unions. The average effective marginal tax rate decreases more for low-skilled workers because for some low-skilled part-time jobs the reform entails a complete cut in supplemental social assistance benefits (see Figure 1). These jobs, which were subject to high marginal transfer withdrawal rates before, thus face a considerable reduction in effective marginal tax rates. This shifts the incentive for unions towards higher wages and away from higher employment for lowskilled workers. In addition, the reform leads to higher unemployment rates ('UR') for both skill types, with the increase being more pronounced for low-skilled labour. Under both modelling approaches the wage responses are thus not sufficiently strong to absorb the additional labour supply.

Comparing the relevance of the general equilibrium effects for the two modelling approaches, we find that general equilibrium repercussions are generally boosted under the logit approach, which corresponds to the overall larger effects on labour supply. Higher labour supply translates into lower equilibrium wages and consequently higher negative feed-back effects on labour supply than in the AWTP case. Moreover, as the logit approach generates larger labour supply effects, it produces less favourable outcomes with respect to unemployment. In the AWTP simulations, the increase in unemployment is only slight, while in the logit simulations it is substantial.

\section{Scenario 2}

Finally, Table 6 reports the general equilibrium outcomes for Scenario 2. Like in Scenario 1, the labour supply responses are mitigated due to the downward adjustment of wages. Unlike Scenario 1, however, Scenario 2 leads to a larger reduction of low-skilled as compared to high-skilled wages. This has two reasons: First, as can be seen from Table 6 , in Scenario 2 the increase in participation rates of low-skilled workers is higher than for the high-skilled. Second, the increases in effective marginal tax rates are higher for low- 
skilled workers ${ }^{7}$, which, according to the tax progression argument, leads to stronger wage moderation for this group. In line with the lower gap in the (partial equilibrium) participation responses, the difference in wages reactions under both approaches is smaller than in Scenario 1. For example, in Scenario 1 the decrease in high-skilled wages that resulted in the logit simulations was three times larger than the wage decrease in the AWTP approach. In Scenario 2, the logit simulations produce a decrease in high-skilled wages that is only about 75 per cent larger. However, despite the narrower gap in general equilibrium repercussions, both approaches lead to qualitatively different conclusions with respect to unemployment.

\begin{tabular}{lcccccccccc}
\hline \hline Individual & \multicolumn{4}{c}{ AWTP } & \multicolumn{1}{c}{ Logit } \\
group & PR & TLS & W & UR & TM & PR & TLS & W & UR & TM \\
\hline Married men & 1.13 & 1.03 & & & & 0.50 & 0.19 & & & \\
Married women & 0.86 & 0.35 & & & & 1.45 & 0.86 & & & \\
Singles & 2.35 & 0.95 & & & & 1.95 & 1.12 & & & \\
Low-skilled & 1.96 & 1.28 & -2.59 & -0.89 & 2.13 & 2.52 & 1.89 & -3.82 & 0.19 & 2.36 \\
High-skilled & 1.27 & 0.77 & -1.54 & -0.09 & 0.75 & 1.03 & 0.46 & -2.68 & 0.11 & 1.00 \\
All & 1.37 & 0.83 & & & & 1.25 & 0.64 & & & \\
\hline \hline
\end{tabular}

PR: participation rate (change in percentage points), TLS: total labour supply in hours (change in per cent), W: gross wage (change in per cent), UR: unemployment rate (change in percentage points), TM: marginal tax rate (change in percentage points)

Table 6: General equilibrium effects (Scenario 2)

While the AWTP approach leads to a decrease in unemployment rates for both skilltypes (with the cut being more pronounced for low-skilled labour), the logit simulations produce the reverse result. Under the AWTP assumptions, the wage reactions are thus sufficiently strong to prevent additional labour supply from translating into higher unemployment, whereas the additional labour supply in the logit setting is too large to be

\footnotetext{
${ }^{7}$ At first glance, the increase in effective marginal tax rates is counterintuitive because Scenario 2 explicitly reduces transfer withdrawal rates and, thus, effective marginal tax rates at the bottom of the income distribution. At the same time, however, social assistance eligibility extends to higher income levels. As a result, effective marginal tax rates may increase for incomes falling between the benchmark and the reform break even income. Whether skill-specific effective marginal tax rates increase or decrease depends on the underlying hours-of-work and household distribution.
} 
absorbed by labour demand. These results illustrate that the underlying assumptions concerning the flexibility of labour supply may not only lead to different results with respect to the labour supply itself, but may also bring about qualitatively diverging shifts of the entire labour market equilibrium.

\section{Conclusions}

We have presented two alternative approaches to discrete working time choice that are suited for an integration into an applied general equilibrium framework. They differ in the way heterogeneity of households (within an socioeconomic type) is captured and in the degree of flexibility between options that they accommodate. In the AWTP variant heterogeneity is produced by an autonomous working time preference parameter, which results in a setting where working time changes are predominantly between adjacent options. In the logit framework, in contrast, household heterogeneity results from an idiosyncratic stochastic utility component, and individuals switch to other options in proportion to their benchmark frequencies.

Within a partial-equilibrium labour supply setup, more advanced econometric tools of discrete choice analysis would be available (Blundell and MaCurdy, 1999). For the use within a general equilibrium framework, however, the options we analyse are the only ones that are numerically tractable at present. In the framework of our model, both approaches share the following advantages of the combination of general equilibrium and micro analysis:

- The extensive and the intensive margin of labour can be distinguished. This is not possible in other models in the AGE tradition, even as elaborated as in Hutton and Ruocco (1999). We can thus break down changes in total labour supply into changes in the participation rate and changes in the average hours of work supplied, as e.g. in Table 2 in Section 5.

- For each individual household a complex budget constraint is formulated, so that the details of national tax and transfer systems can be integrated in the model. This is especially important for couple households, for which tax and transfer rules depend on the household composition as well as the labour market status of both spouses. 
- Complex interactions are captured for the economy as a whole. Labour supply changes affect different sectors of the economy differently, with sectoral factor demand and international trade consequences. The public budget is affected both directly through reform policies and indirectly through their consequences throughout the whole economy.

Despite these similarities of the two approaches, the scenario outcomes from their comparative application in Section 5 are divergent in some important respects. This can mainly be traced back to the fundamental dissimilarity in treating switches between options: In AWTP, individuals are constrained to switch beween adjacent options, whereas in the logit setup, switches between all options are possible.

- In general, the labour supply reactions in the logit setup are stronger than in the AWTP model, although the partial elasticities used to calibrate the AWTP model have been derived from the logit parameters.

- The differences in the simulated changes in the participation rates are moderate as long as the relevant changes in relative disposable incomes are between nonparticipation and the lowest positive working time category (as in Scenario 2). Otherwise (Scenario 1), the discepancy between the model outcomes can be considerable.

- Concerning the differences in the simulated average hours of work, under the AWTP approach, an increase in the participation rate comes along with a reduction in average working time because switches are only into the lowest working time category. Under the logit approach this is not necessarily the case since individuals may switch to all possible working hours categories.

Both modelling variants are plausible formulations of household heterogeneity, and their value for applied work cannot be judged a priori. The decisive question is whether our empirical knowledge of actual reaction patterns in labour supply is so detailed that we can use it for discrimination. As the two approaches are not nested, it is difficult to directly test them against one another. In principle, such a test could proceed along the lines of a test of the IIA (independence from irrelevant alternatives) implication of simple conditional logit, but even in the relatively simple case of IIA it is difficult to draw clear conclusions from the results (Train, 2003, p.53). Given the sparse econometric evidence 
on reaction patterns in the literature, we must rely on indirect arguments that are more favourable for the logit than for the AWTP approach:

- The restrictions on labour supply behaviour that results from the functional form in the AWTP approach seem considerably more severe. It is clearly counterfactual that households only change between adjacent labour supply options.

- Given that the calibration data for the model are produced with logit simulations (according to the standard econometric approach), there are some compatibility problems that weaken the empirical foundation of the AWTP model. To a certain degree it is arbitrary which elasticities one chooses for calibration; and it is burdensome to check whether other elasticities would make a difference. When we use partial elasticities for calibration, the AWTP parameterisation is such that simulated elasticities can only be approximated to a certain degree (see the comparison of simulated and calibrated elasticity values in Appendix A.4).

- The AWTP approach requires that we disassemble the simultaneous maximisation problem of the household into two independent working time choices of the partners. This is done by assuming that when one partner chooses their optimal working time, they take the other partner's income and leisure to be constant at their conditional expected values given the benchmark probabilities. Otherwise multiple equilibria might arise for which an explicit choice mechanism would have to be set up.

Against this background of difficulties with the AWTP approach, the logit alternative is preferable. The main advantage results from its direct compatibility with the underlying estimation and simulation of labour supply reactions in a standard microsimulation model. The problems of the logit setup - mainly the IIA implication - is less severe and can be approached using established econometric techniques. All in all, we see the logit approach as the more promising option in a general equilibrium framework combining comprehensiveness, detail and consistency in applied research. 


\section{References}

[1] Ballard, Charles L., Don Fullerton, John B. Shoven and John Whalley (1985): A General Equilibrium Model for Tax Policy Evaluation, The University of Chicago Press, National Bureau of Economic Research

[2] Blundell, Richard and Thomas MaCurdy (1999): Labor Supply: A Review of Alternative Approaches, in: Ashenfelter, Orley and David Card (eds.): Handbook of Labor Economics, Vol. 3, Amsterdam (Elsevier), 1559-1695

[3] Boeters, Stefan, Nicole Gürtzgen and Reinhold Schnabel (2003): Reforming Social Welfare in Germany - An Applied General Equilibrium Analysis, ZEW Discussion Paper 03-70, Mannheim

[4] Boeters, Stefan, Michael Feil and Nicole Gürtzgen (2004): Discrete Working Time Choice in an Applied General Equilibrium Model, ZEW Discussion Paper No. 04-20, Mannheim

[5] Böhringer, Christoph, Stefan Boeters and Michael Feil (2005): Taxation and Unemployment: An Applied General Equilibrium Approach for Germany, Economic Modelling 22, 81-108

[6] Bovenberg, A. Lans, Johan J. Graafland and Ruud A. de Mooij (2000): Tax reform and the Dutch labor market : an applied general equilibrium approach, Journal of Public Economics 78, 193-214

[7] Buslei, Hermann and Viktor Steiner (1999): Beschäftigungseffekte von Lohnsubventionen im Niedriglohnbereich, Baden-Baden: Nomos

[8] De Ceuster, Griet, Bart Van Herbruggen, Steven Logghe, Stef Proost (2004): TREMOVE, Report for European Commission, DG ENV, Transport \& Mobility Leuven and K.U. Leuven

[9] Graafland, Johan J., Ruud A. de Mooij (1999): Fiscal Policy and the labour market: An AGE analysis, Economic Modelling 16, 189-219

[10] Graafland, Johan J., Ruud A. de Mooij, André G.H. Nibbelink and Ate Nieuwenhuis (2001): MIMICing Tax Policies and the Labour Market, Amsterdam: Elsevier

[11] Gupta, Anil, and Vishnu Kapur (ed.) (2000): Microsimulation in Government Policy and Forecasting, Amsterdam: Elsevier 
[12] Hutton, John P., and Anna Ruocco (1999): Tax Reform and Employment in Europe, International Tax and Public Finance 6, 263-287

[13] Immervoll, Herwig, Henrik Kleven, Claus T. Kreiner, and Emmanuel Saez (2004): Welfare Reform in European Countries: A Microsimulation Analysis, CEPR Discussion Paper No. 4324

[14] Kleven, Henrik J., and Claus T. Kreiner (2003): The Marginal Cost of Public Funds in OECD Countries: Hours of Work Versus Labor Force Participation, CESifo Working Paper No. 935

[15] Koskela, Erkki and Jouko Vilmunen (1996): Tax Progression is Good for Employment in Popular Models of Trade Union Behaviour, Labour Economics 3, 65-80

[16] Lejour, Arjan, Nico van Leeuwen, Ton Manders, Guido van Steen, Hans Timmer and Gerard Verweij (1999): WorldScan - the core version, CPB Netherlands Bureau for Economic Policy Analysis, Den Haag

[17] McFadden, Daniel (1974): Conditional logit analysis of qualitative choice behavior, in: P. Zarembka (ed.), Frontiers in Econometrics, New York: Academic Press, 105-142

[18] Nickell, Steve, and Jan van Ours (2000): The Netherlands and the United Kingdom: a European unemployment miracle?, Economic Policy 30, 137-180

[19] OECD (2004): OECD Employment Outlook, Paris

[20] Pissarides, Christopher A. (1990): Equilibrium unemployment theory, Oxford: Basil Blackwell

[21] Saez, Emmanuel (2002): Optimal Income Transfer Programs: Intensive versus Extensive Labour Supply Responses, Quarterly Journal of Economics 117, 1039-1073

[22] Shoven, John B., and John Whalley (1984): Applied General-Equilibrium Models of Taxation and International Trade: An Introduction and Survey, Journal of Economic Literature 22, 1007-1051

[23] Steiner, Viktor, and P. Jacobebbinghaus. (2003): Reforming Social Welfare as we know it? A Microsimulation Study for Germany, ZEW Discussion Paper 03-33, Mannheim

[24] Train, Kenneth (2003): Discrete Choice Methods with Simulation, Cambridge: Cambridge University Press 
[25] van Soest, Arthur (1995): Structural models of family labor supply : a discrete choice approach, Journal of human resources, 30, 63-88 


\section{A Appendix}

\section{A.1 Household classification for labour supply module}

\begin{tabular}{ll}
\hline \hline Abbreviation & Definition \\
\hline CijxK & couple, woman skill group i, man skill group $\mathrm{j}, \mathrm{x}$ children \\
$\mathrm{Mi} 0$ & male single, skill group $\mathrm{i}$, no children \\
$\mathrm{WiO}$ & female single, skill group $\mathrm{i}$, no children \\
$\mathrm{xKi}$ & single (male or female), skill group i, $\mathrm{x}$ children \\
\hline \hline $\mathrm{i}=\mathrm{L}$ (low skilled), H (high skilled), $\mathrm{x}=0,1,2$ or more
\end{tabular}

Table 7: Household Disaggregation

\section{A.2 Working hours options for different household types}

\begin{tabular}{llllll}
\hline \hline Individual & \multicolumn{5}{c}{ Hours Options } \\
\hline men, married or single without children & 0 & & & 38 & 49 \\
men, single with children & 0 & 15 & 30 & 38 & 47 \\
women, single & 0 & 15 & 30 & 38 & 47 \\
women, married & 0 & 9.5 & 24 & 38 & 47 \\
\hline \hline
\end{tabular}

Table 8: Discrete Working Hours by Household Types 


\section{A.3 Estimation results from the microsimulation model}

\begin{tabular}{|c|c|c|c|c|}
\hline & Coef. & $\mathrm{SE}$ & $\mathrm{z}$ & $\mathrm{P}>\mathrm{z}$ \\
\hline Net household income & \begin{tabular}{c|}
-6.44 \\
\end{tabular} & 1.85 & 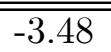 & $\overline{0.001}$ \\
\hline Net household income^2 & 0.43 & 0.08 & 5.22 & 0.000 \\
\hline Net hh income $\mathrm{X}$ leisure & 0.48 & 0.30 & 1.63 & 0.103 \\
\hline Leisure X East Germany & -0.96 & 0.29 & -3.32 & 0.001 \\
\hline Leisure X nationality & 0.23 & 0.41 & 0.57 & 0.566 \\
\hline Leisure & 77.59 & 14.10 & 5.50 & 0.000 \\
\hline Leisure^2 & -9.96 & 1.80 & -5.55 & 0.000 \\
\hline Leisure $\mathrm{X}$ age & -1.11 & 0.31 & -3.65 & 0.000 \\
\hline Leisure $\mathrm{X}$ age ${ }^{\wedge} 2$ & 0.10 & 0.04 & 2.42 & 0.016 \\
\hline Leisure^2 $\mathrm{X}$ age & 0.59 & 0.12 & 4.83 & 0.000 \\
\hline Leisure X handicapped & -0.17 & 0.90 & -0.18 & 0.853 \\
\hline Leisure $\mathrm{X}$ children $<6$ years & 4.99 & 0.60 & 8.32 & 0.000 \\
\hline Leisure X children 7-16 years & 1.50 & 0.35 & 4.29 & 0.000 \\
\hline Leisure $\mathrm{X}$ children $>=17$ years & -0.48 & 0.31 & -1.53 & 0.127 \\
\hline Dummy for employment & -2.13 & 0.25 & -8.67 & 0.000 \\
\hline Number of obs. & \multicolumn{4}{|c|}{540} \\
\hline Log Likelihood & \multicolumn{4}{|c|}{-636.0} \\
\hline
\end{tabular}

Table 9: Maximum Likelihood Estimates for single females 


\begin{tabular}{|c|c|c|c|c|}
\hline & Coef. & $\mathrm{SE}$ & $\mathrm{z}$ & $\mathrm{P}>\mathrm{z}$ \\
\hline Net household income & 6.76 & 2.73 & 2.48 & 0.013 \\
\hline Net household income`2 & -0.019 & 0.10 & -0.19 & 0.848 \\
\hline Net hh income $\mathrm{X}$ leisure & -1.42 & 0.44 & -3.21 & 0.001 \\
\hline Leisure & 169.71 & 20.03 & 8.47 & 0.000 \\
\hline Leisure ${ }^{\wedge} 2$ & -21.13 & 2.60 & -8.12 & 0.000 \\
\hline Leisure X East Germany & -0.05 & 0.33 & -0.15 & 0.881 \\
\hline Leisure X nationality & 0.29 & 0.48 & 0.60 & 0.547 \\
\hline Leisure $\mathrm{X}$ age & -0.74 & 0.32 & -2.34 & 0.019 \\
\hline Leisure $\mathrm{X}$ age^2 & 0.41 & 0.12 & 3.35 & 0.001 \\
\hline Leisure^2 $\mathrm{X}$ age & 0.06 & 0.04 & 1.46 & 0.143 \\
\hline Leisure X handicapped & 1.32 & 0.83 & 1.60 & 0.110 \\
\hline Dummy for employment & -9.96 & 1.13 & -8.78 & 0.000 \\
\hline Number of obs. & \multicolumn{4}{|c|}{952} \\
\hline Log Likelihood & \multicolumn{4}{|c|}{-1286.7} \\
\hline
\end{tabular}

Table 10: Maximum Likelihood Estimates for single males 


\begin{tabular}{|c|c|c|c|c|}
\hline & Coef. & $\mathrm{SE}$ & $\mathrm{z}$ & $\mathrm{P}>\mathrm{z}$ \\
\hline Net household income & 8.95 & 5.11 & 1.75 & 0.080 \\
\hline Net household income^2 & -0.003 & 0.26 & -0.01 & 0.989 \\
\hline Net hh income $\mathrm{X}$ leisure of male spouse & -1.46 & 0.42 & -3.46 & 0.001 \\
\hline Net hh income $\mathrm{X}$ leisure of female spouse & -0.43 & 0.38 & -1.14 & 0.253 \\
\hline Net hh income X nationality & -6.92 & 3.82 & -1.81 & 0.070 \\
\hline Net hh income^2 $\mathrm{X}$ nationality & 0.56 & 0.27 & 2.09 & 0.036 \\
\hline Net hh income X East Germany & 5.50 & 1.87 & 2.94 & 0.003 \\
\hline Net hh income`2 X East Germany & -0.49 & 0.14 & -3.37 & 0.001 \\
\hline Leisure of male spouse & 56.72 & 7.15 & 7.94 & 0.000 \\
\hline Leisure of male spouse`2 & -4.06 & 0.47 & -8.66 & 0.000 \\
\hline Leisure of male spouse X nationality & -0.40 & 0.41 & -0.98 & 0.328 \\
\hline Leisure of male spouse X East Germany & -6.05 & 2.80 & -2.16 & 0.031 \\
\hline Leisure of male spou & -0.36 & 0.08 & -4.31 & 0.000 \\
\hline Leisure of male spouse $\mathrm{X}$ ag & 0.48 & 0.10 & 4.99 & 0.000 \\
\hline Leisure of male spouse $\mathrm{X}$ handicapped & 0.76 & 0.72 & 1.06 & 0.290 \\
\hline Leisure of female spouse & 79.98 & 7.00 & 11.43 & 0.000 \\
\hline Leisure of female & -8.40 & 0.53 & -15.77 & 0.000 \\
\hline Leisure of femal & 0.27 & 0.40 & 0.67 & 0.501 \\
\hline Leisure of female spouse X East Germany & -7.10 & 2.59 & -2.74 & 0.006 \\
\hline Leisure of female spouse $\mathrm{X}$ age & -0.39 & 0.09 & -4.18 & 0.000 \\
\hline Leisure of female spouse $\mathrm{X}$ age^ 2 & 0.58 & 0.11 & 5.26 & 0.000 \\
\hline Leisure of female spouse X handicapped & 0.97 & 0.71 & 1.36 & 0.175 \\
\hline Leisure of female spouse $\mathrm{X}$ children $<6$ ye & 4.63 & 0.31 & 14.98 & 0.000 \\
\hline Leisure of female spouse $\mathrm{X}$ children $7-16$ years & 2.13 & 0.22 & 9.59 & 0.000 \\
\hline Leisure of female spouse $\mathrm{X}$ children $>=17$ years & -0.56 & 0.22 & -2.56 & 0.011 \\
\hline Leisure of male spouse X Leisure of female spouse & -1.50 & 0.55 & -2.72 & 0.006 \\
\hline & & & & \\
\hline $\mathrm{X}$ Leisure of female spouse $\mathrm{X}$ nationality & 0.26 & 0.14 & 1.78 & 0.075 \\
\hline Leisure of male spouse & & & & \\
\hline of female spouse X East Germany & 1.03 & 0.70 & 1.47 & 0.142 \\
\hline Dummy for employment of female spouse & -2.55 & 0.25 & -10.09 & 0.000 \\
\hline Dummy for employment of both spouses & 0.61 & 0.24 & 2.54 & 0.011 \\
\hline Number of obs. & \multicolumn{4}{|c|}{1910} \\
\hline Log Likelihood & \multicolumn{4}{|c|}{-4186.1} \\
\hline
\end{tabular}

Conditional logit with fifteen hours-of-work options (female spouse: 0, 9.5, 47; male spouse: 0, 38, 49), SOEP 1999

Table 11: Maximum Likelihood Estimates for couples 


\section{A.4 Comparison of simulated and calibrated elasticities}

\begin{tabular}{|c|c|c|c|c|c|c|c|c|c|c|c|c|}
\hline \multirow[b]{2}{*}{ Household } & \multicolumn{4}{|c|}{ Elasticities Men } & \multicolumn{8}{|c|}{ Elasticities Women } \\
\hline & $1(\mathrm{~s})$ & $1(\mathrm{c})$ & $2(\mathrm{~s})$ & $2(\mathrm{c})$ & $1(\mathrm{~s})$ & $1(\mathrm{c})$ & $2(\mathrm{~s})$ & $2(\mathrm{c})$ & $3(\mathrm{~s})$ & $3(\mathrm{c})$ & $4(\mathrm{~s})$ & $4(\mathrm{c})$ \\
\hline CLL0K & 0.31 & 0.35 & 0.29 & 0.21 & 0.01 & 0.03 & 0.14 & 0.06 & 0.15 & 0.15 & 0.07 & 0.09 \\
\hline CLHOK & 0.50 & 0.64 & 0.62 & 0.41 & 0.03 & 0.07 & 0.17 & 0.15 & 0.24 & 0.25 & 0.17 & 0.13 \\
\hline CHLOK & 0.40 & 0.45 & 0.49 & 0.44 & 0.03 & 0.01 & 0.21 & 0.16 & 0.31 & 0.34 & 0.22 & 0.19 \\
\hline СHHOK & 0.48 & 0.62 & 0.63 & 0.43 & 0.02 & 0.05 & 0.17 & 0.16 & 0.24 & 0.27 & 0.18 & 0.13 \\
\hline CLL1K & 0.29 & 0.35 & 0.33 & 0.22 & 0.00 & 0.03 & 0.08 & 0.06 & 0.09 & 0.10 & 0.06 & 0.05 \\
\hline CLH1K & 0.47 & 0.60 & 0.59 & 0.39 & 0.00 & 0.07 & 0.13 & 0.11 & 0.16 & 0.10 & 0.08 & 0.04 \\
\hline CHL1K & 0.36 & 0.47 & 0.49 & 0.36 & 0.02 & 0.08 & 0.15 & 0.14 & 0.21 & 0.15 & 0.13 & 0.06 \\
\hline CHH1K & 0.44 & 0.56 & 0.57 & 0.39 & 0.02 & 0.08 & 0.14 & 0.15 & 0.18 & 0.16 & 0.11 & 0.06 \\
\hline CLL2K & 0.31 & 0.39 & 0.37 & 0.25 & 0.01 & 0.06 & 0.07 & 0.04 & 0.09 & 0.03 & 0.05 & 0.01 \\
\hline CLH2K & 0.52 & 0.69 & 0.70 & 0.42 & 0.00 & 0.07 & 0.13 & 0.08 & 0.15 & 0.06 & 0.08 & 0.01 \\
\hline CHL2K & 0.43 & 0.57 & 0.62 & 0.42 & 0.03 & 0.11 & 0.17 & 0.18 & 0.20 & 0.16 & 0.10 & 0.04 \\
\hline CHH2K & 0.49 & 0.63 & 0.65 & 0.46 & 0.02 & 0.09 & 0.13 & 0.12 & 0.16 & 0.11 & 0.09 & 0.04 \\
\hline CLL3K & 0.20 & 0.18 & 0.26 & 0.28 & 0.00 & 0.05 & 0.07 & 0.06 & 0.11 & 0.02 & 0.06 & 0.00 \\
\hline CLH3K & 0.49 & 0.62 & 0.61 & 0.42 & 0.01 & 0.07 & 0.09 & 0.03 & 0.10 & 0.02 & 0.04 & 0.00 \\
\hline CHL3K & 0.26 & 0.30 & 0.36 & 0.32 & 0.02 & 0.07 & 0.12 & 0.05 & 0.14 & 0.00 & 0.05 & 0.00 \\
\hline СНH3K & 0.44 & 0.57 & 0.58 & 0.38 & 0.02 & 0.06 & 0.09 & 0.11 & 0.10 & 0.07 & 0.05 & 0.01 \\
\hline ML0 & - & - & - & - & 0.00 & 0.01 & 0.01 & 0.10 & 0.19 & 0.23 & 0.25 & 0.12 \\
\hline MH0 & - & - & - & - & 0.01 & 0.00 & 0.01 & 0.11 & 0.20 & 0.24 & 0.27 & 0.13 \\
\hline WL0 & - & - & - & - & 0.05 & 0.03 & 0.20 & 0.17 & 0.23 & 0.27 & 0.18 & 0.14 \\
\hline WH0 & - & - & - & - & 0.05 & 0.01 & 0.26 & 0.25 & 0.33 & 0.39 & 0.29 & 0.19 \\
\hline $1 \mathrm{KL}$ & - & - & - & - & 0.05 & 0.01 & 0.13 & 0.10 & 0.14 & 0.17 & 0.09 & 0.07 \\
\hline $1 \mathrm{KH}$ & - & - & - & - & 0.04 & 0.02 & 0.16 & 0.20 & 0.23 & 0.24 & 0.19 & 0.11 \\
\hline $2 \mathrm{KL}$ & - & - & - & - & 0.03 & 0.03 & 0.16 & 0.00 & 0.24 & 0.08 & 0.22 & 0.00 \\
\hline $2 \mathrm{KH}$ & - & - & - & - & 0.01 & 0.01 & 0.05 & 0.07 & 0.07 & 0.06 & 0.06 & 0.02 \\
\hline $3 \mathrm{KL}$ & - & - & - & - & 0.03 & 0.03 & 0.10 & 0.00 & 0.16 & 0.00 & 0.18 & 0.00 \\
\hline $3 \mathrm{KH}$ & - & - & - & - & 0.02 & 0.02 & 0.04 & 0.00 & 0.02 & 0.05 & 0.09 & 0.04 \\
\hline
\end{tabular}

1, 2, 3, 4: positive time categories, (s): simulated elasticities, (c): calibrated elasticities

elasticity values are to be read like this: change of labour supply probability in one category in percentage points as a reaction to a one per cent change of the wage in the respective category

Table 12: Partial labour supply elasticities 


\section{A.5 Aggregated coefficients of logit utility function}

\begin{tabular}{|c|c|c|c|c|c|c|c|c|c|c|c|}
\hline Household & $\beta(C)$ & $\beta\left(l_{f}\right)$ & $\beta\left(l_{m}\right)$ & $A\left(C^{2}\right)$ & $A\left(C l_{f}\right)$ & $A\left(C l_{m}\right)$ & $A\left(l_{f}^{2}\right)$ & $A\left(l_{f} l_{m}\right)$ & $A\left(l_{m}^{2}\right)$ & $d_{f}$ & $d_{f m}$ \\
\hline CLLOK & 5.25 & 76.4 & 51.4 & 0.29 & -0.43 & -1.46 & -8.40 & -1.37 & -4.06 & -2.55 & 0.61 \\
\hline CLHOK & 2.76 & 74.9 & 50.1 & 0.49 & -0.43 & -1.46 & -8.40 & -1.19 & -4.06 & -2.55 & 0.61 \\
\hline CHLOK & 2.80 & 74.5 & 49.9 & 0.49 & -0.43 & -1.46 & -8.40 & -1.16 & -4.06 & -2.55 & 0.61 \\
\hline СHH0K & 3.08 & 74.2 & 49.4 & 0.46 & -0.43 & -1.46 & -8.40 & -1.08 & -4.06 & -2.55 & 0.61 \\
\hline CLL1K & 7.28 & 75.8 & 51.0 & 0.13 & -0.43 & -1.46 & -8.40 & -1.44 & -4.06 & -2.55 & 0.61 \\
\hline CLH1K & 3.38 & 75.8 & 50.0 & 0.44 & -0.43 & -1.46 & -8.40 & -1.24 & -4.06 & -2.55 & 0.61 \\
\hline CHL1K & 4.07 & 74.3 & 48.8 & 0.38 & -0.43 & -1.46 & -8.40 & -1.05 & -4.06 & -2.55 & 0.61 \\
\hline CHH1K & 3.72 & 74.2 & 48.3 & 0.41 & -0.43 & -1.46 & -8.40 & -0.94 & -4.06 & -2.55 & 0.61 \\
\hline CLL2K & 6.28 & 76.1 & 50.5 & 0.21 & -0.43 & -1.46 & -8.40 & -1.40 & -4.06 & -2.55 & 0.61 \\
\hline CLH2K & 3.05 & 76.2 & 49.7 & 0.47 & -0.43 & -1.46 & -8.40 & -1.25 & -4.06 & -2.55 & 0.61 \\
\hline CHL2K & 2.71 & 76.1 & 49.3 & 0.50 & -0.43 & -1.46 & -8.40 & -1.21 & -4.06 & -2.55 & 0.61 \\
\hline CHH2K & 3.42 & 75.0 & 48.5 & 0.43 & -0.43 & -1.46 & -8.40 & -1.03 & -4.06 & -2.55 & 0.61 \\
\hline CLL3K & 7.63 & 76.5 & 50.3 & 0.10 & -0.43 & -1.46 & -8.40 & -1.45 & -4.06 & -2.55 & 0.61 \\
\hline CLH3K & 2.95 & 78.1 & 50.0 & 0.48 & -0.43 & -1.46 & -8.40 & -1.28 & -4.06 & -2.55 & 0.61 \\
\hline CHL3K & 4.12 & 76.4 & 48.9 & 0.38 & -0.43 & -1.46 & -8.40 & -1.17 & -4.06 & -2.55 & 0.61 \\
\hline СНH3K & 3.09 & 76.8 & 48.7 & 0.46 & -0.43 & -1.46 & -8.40 & -1.08 & -4.06 & -2.55 & 0.61 \\
\hline ML0 & 6.76 & 148.2 & - & -0.02 & -1.42 & - & - & -18.92 & - & -9.96 & - \\
\hline МH0 & 6.76 & 147.2 & - & -0.02 & -1.42 & - & - & -18.78 & - & -9.96 & - \\
\hline WL0 & -6.44 & 38.0 & - & 0.43 & 0.48 & - & - & -5.22 & - & -2.13 & - \\
\hline WH0 & -6.44 & 42.8 & - & 0.43 & 0.48 & - & - & -6.03 & - & -2.13 & - \\
\hline $1 \mathrm{KL}$ & -5.96 & 46.9 & - & 0.41 & 0.41 & - & - & -6.23 & - & -2.42 & - \\
\hline $1 \mathrm{KH}$ & -4.09 & 60.8 & - & 0.35 & 0.14 & - & - & -8.19 & - & -3.52 & - \\
\hline $2 \mathrm{KL}$ & -3.80 & 62.9 & - & 0.34 & 0.10 & - & - & -8.42 & - & -3.70 & - \\
\hline $2 \mathrm{KH}$ & -4.01 & 61.2 & - & 0.35 & 0.13 & - & - & -8.13 & - & -3.57 & - \\
\hline $3 \mathrm{KL}$ & -6.36 & 49.0 & - & 0.43 & 0.47 & - & - & -6.33 & - & -2.18 & - \\
\hline $3 \mathrm{KH}$ & -5.64 & 51.5 & - & 0.40 & 0.37 & - & - & -6.99 & - & -2.61 & - \\
\hline
\end{tabular}

Table 13: Aggregated parameters of the utility function 


\section{A.6 The formulation of the individual household's budget con- straint}

Gross monthly earnings are obtained by multiplying the gross hourly wage with monthly hours of work corresponding to the respective category of weekly labour supply. As we distinguish low and high-skilled labour, gross individual income does not only depend on the chosen category of hours worked, but also on individual qualification. Low-skilled workers are defined as persons without any formal vocational training, whereas individuals holding a vocational or university degree are assumed to be high-skilled. Gross hourly wages are assumed uniform at $10.8 €$ for low skilled and $14.3 €$ for high skilled. These are average wages for the respective qualification levels in the German SOEP for the year 2000 .

To obtain net earnings per month, income taxes and social security contributions are deducted from gross monthly earnings. The share in social security contributions borne by employees is taken to amount to 20 per cent of gross monthly earnings. In 2000, gross monthly earnings of $325 €$ were exempted from social security contributions. Income taxes are calculated on the basis of taxable income, which is obtained by subtracting a standard deduction from gross earnings. To determine income taxes paid by each household type, we apply the German income tax schedule from the benchmark year 2000 to taxable earnings. For couple households, income tax legislation allows for marital income splitting: According to this method, the tax schedule is applied to half of the joint taxable income, while the resulting tax amount is doubled to obtain total income taxes paid by the couple.

Finally, disposable monthly earnings are obtained by adding transfer payments to net monthly labour earnings The most important transfer payments in Germany include unemployment insurance ("Arbeitslosengeld"), unemployment assistance ("Arbeitslosenhilfe"), social assistance ("Sozialhilfe"), housing benefits ("Wohngeld") and child benefits ("Kindergeld"). In our model, we account for unemployment benefits and assistance, social assistance and child benefits, while housing benefits are neglected.

In Germany, unemployment benefits (UB) are available for persons who have paid contributions to the statutory unemployment insurance for a minimum of one year. In particular, the duration of unemployment benefits depends on the unemployed person's former labour market experience and age. The monthly amount received equals a constant fraction of previous net monthly earnings. At present, the replacement rate for persons without children is 60 per cent and for persons with children 67 per cent. Unemployment benefits are not means-tested. The entitlement to unemployment benefits is thus 
completely independent from the labour or transfer income received by the respective spouse.

For those persons who do not have enough experience to obtain unemployment benefits or who have exhausted their unemployment benefits, unemployment assistance (UA) and social assistance (SA) become relevant. The replacement rate for UA payments for persons without children is 53 per cent and for persons with children 57 per cent. In contrast to unemployment benefits, both welfare payments are means-tested, i.e. payments are reduced if either the unemployed person or remaining household members receive other incomes. While UA is only available for those persons who have exhausted their unemployment benefits, eligibility for SA does not require any former entitlement to unemployment benefits. Our model takes into account the means-tested nature of SA payments, but neglects the means-tested nature of UA payments. To incorporate the different transfer components in our model, we proceed as follows: first, we assign SA payments to all voluntarily unemployed singles and to those couple households whose adult members are both voluntarily unemployed. Second, for positive hours of labour supply we distinguish three labour market states: a person who supplies a positive number of hours worked may be employed, which will be denoted as state $(e)$. If the individual does not find a job and becomes involuntarily unemployed, he or she may either be entitled to UB or UA $(b)$ or receive SA payments $(n)$. In a static model, we are not able to determine the entitlement to UB or UA due to former contributions to the statutory unemployment insurance. Instead, we assume that a person who becomes unemployed is entitled to unemployment benefits or unemployment assistance with an exogenous probability $P_{U}$, and receives SA payments with probability $\left(1-P_{U}\right)$. In the former case, UB and UA payments are determined by the replacement ratio of the net income that corresponds to the chosen category of hours of labour supplied. More specifically, this replacement ratio is defined as a weighted average of UB and UA replacement rates where the weights are the respective empirical shares of persons entitled to UA or UB. SA payments, in contrast, do not depend on the category of hours supplied in the labour market.

The distinction of three labour market states requires that the value of disposable income for a particular category of working time be calculated as an expected value. For singles, the expected value of the disposable income for a particular category of hours of work supplied is determined as a weighted average of the disposable income values in the three labour market states $(e, b$ and $n)$, with the respective probabilities, $P(i), i=e, b, n$, as weights: 


$$
E\left(y\left(h_{k}\right)\right)=\sum_{i=e, b, n} P(i) y^{D}\left(h_{k}, i\right), \quad i=e, b, n
$$

More specifically, we have $P(w)=(1-u), P(b)=u P_{U}$ and $P(n)=u\left(1-P_{U}\right)$, with $u$ representing the (household type specific) unemployment rate. For couples, the expected disposable income for a particular combination of hours of work is determined by the weighted average of disposable incomes corresponding to the 9 combinations of labour market states:

$$
E\left(y^{d}\left(h_{k}^{f}, h_{l}^{m}\right)\right)=\sum_{i, j=e, b, n} P(i) P(j) y^{D}\left(h_{k}^{f}, h_{l}^{m}, i, j\right), \quad i, j=e, b, n
$$

